\title{
Graphical representation of online discussion threads from an academic course in a constructivist setting
}

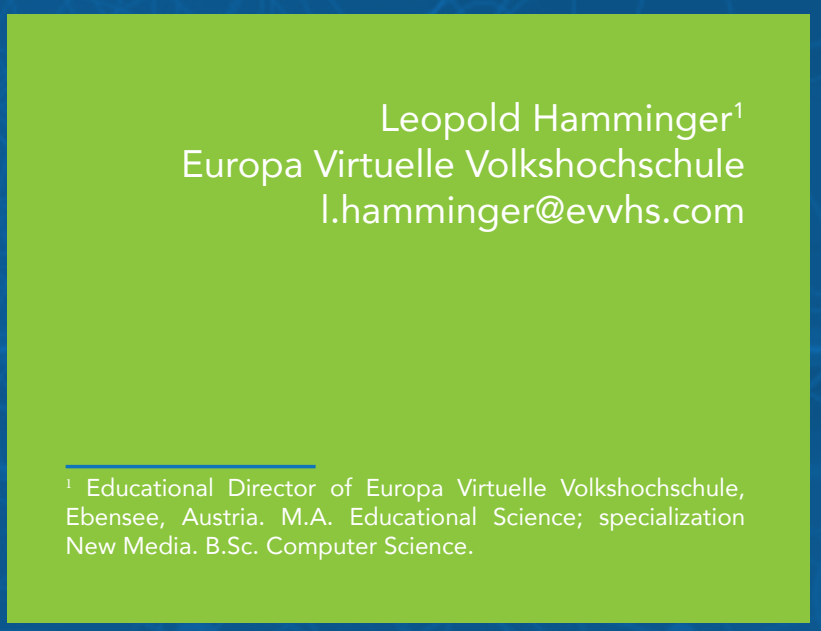

Cómo citar este artículo: Hamminger, L.. (2016). Graphical representation of online discussion threads from an academic course in a constructivist setting. Revista Virtualmente, 4(2), 6-21. 


\section{ABSTRACT}

Constructivist teaching in virtual environments places particular emphasis on the use of discussion forums. This article presents the implementation of a concept of constructivist didactics through an e-learning course on the Blackboard platform of the Department of Education at the University of Salzburg, Austria.

Students were motivated to build knowledge through their participation in discussion forums on the Blackboard platform. Teachers, in their role of moderators, expected to be able to gradually reduce their presence in the debates.

The challenge was to be able to measure the extent to which this was achieved, considering that thousands of discussion contributions had to be analyzed. This document describes how the discussion lines can be extracted from Blackboard to be used by UCINET software for social network and thus produce a graphic presentation of the discussion sequences.

Keywords: e-learning, constructivist teaching, social networking, discussion forum, computeraided communication, Blackboard, TeachNOW, UCINET. 


\section{Representación gráfica de los hilos de discusión en línea, de un curso académico en un contexto constructivista}

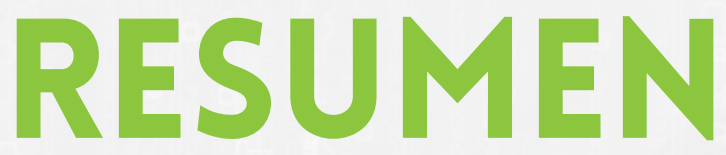

La enseñanza constructivista en ambientes virtuales hace especial énfasis en el uso de los foros de discusión. En este artículo se presenta la implementación de un concepto de didáctica constructivista a través de un curso de e-learning en la plataforma Blackboard del Departamento de educación de la Universidad de Salzburgo, Austria.

Los estudiantes fueron motivados a que construyeran conocimiento a través de la participación en foros de discusión de la plataforma Blackboard. Los docentes, en su rol de moderadores, esperaban poder reducir gradualmente su presencia en los debates.

El reto consistió en ser capaces de medir el grado en que esto se logró, considerando que miles de contribuciones de debate debían ser analizadas. Este documento describe cómo las líneas de discusión pueden ser extraídas de Blackboard para ser usadas por la red social software UCINET y así producir una presentación gráfica de las secuencias de discusión.

Palabras clave: e-learning, enseñanza constructivista, redes sociales, foro de discusión, comunicación asistida por computador, Blackboard, TeachNOW, UCINET. 


\section{Représentation graphique des forums de discussion virtuelle étudiés depuis les concepts académique du constructivisme}

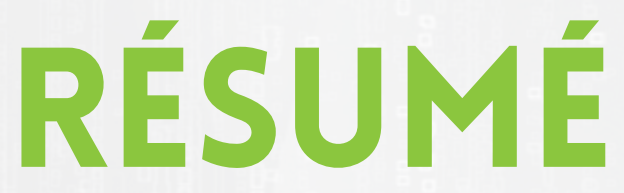

L'enseignement constructiviste en environnements virtuels d'apprentissage met en valeur l'importance de l'utilisation des forums de discussion. Nous présenterons dans cet article la mise en place d'un concept didactico-constructiviste au travers d'un cours d'apprentissage virtuel sur la plate-forme Blackboard du département d'éducation de l'Université de Salzbourg, en Autriche.

Les étudiants ont été incités à construire leurs connaissances au travers de la participation à des forums de discussion sur la plate-forme Blackboard. Les enseignants-modérateurs espéraient pouvoir réduire graduellement leur présence dans les débats.

Le défi consista à mesurer le pourcentage de réussite tenant compte du fait que des milliers de contributions au débat devaient être analysées. Ce document décrit la façon dont les lignes de discussion peuvent être extraites de Blackboard pour être utilisées par le logiciel UCINET et créer ainsi une présentation graphique des séquences de discussion.

Mots clefs: apprentissage virtuel, enseignement constructiviste, réseaux sociaux, forum de discussion, communication assistée par ordinateur, Blackboard, TeachNOW, UCINET. 


\section{Representação gráfica de tópicos de discussão on-line a partir de um curso acadêmico em um cenário construtivista}

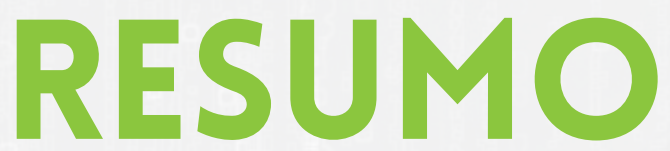

O ensino construtivista em ambientes virtuais coloca ênfase especial no uso de fóruns de discussão. Este artigo discute a implementação de um conceito de ensino construtivista apresentado através de um curso de e-learning na plataforma Blackboard do Departamento de Educação da Universidade de Salzburg, Áustria.

Os alunos foram motivados a construir o conhecimento através da participação em fóruns de discussão na plataforma Blackboard. Os professores, no seu papel de moderadores, esperavam reduzir gradualmente sua presença nos debates.

O desafio consistiu em ser capazes de medir o grau em que isto foi conseguido, considerando que milhares de contribuições para a discussão deveriam ser analisadas. Este documento descreve como tópicos de discussão podem ser extraídos da plataforma Blackboard para ser usados pelo software de rede sociais UCINET e assim produzir uma apresentação gráfica das sequências de discussão.

Palavras-chave: inteligência emocional, formação, competências, desempenho, aprendizagem, habilidades, liderança. 


\section{Introduction}

In a constructivist learning setting, teachers are expected to move from being instructors to being moderators, preparing an environment that is conducive for students so they can build their own knowledge. Learning processes may take place individually, as learners do their research and study by themselves. Numerous cases for the social interaction between moderators and students have taken place, in order to improve these processes. Brown, Collins, and Duguid (1989) in Ugoretz (2005) are of the opinion that "discussion is uniquely suited for learning that it advances through collaborative social interaction and the social construction of knowledge". Ugoretz also makes a point in favor of discussion contributions that digress from the topic: "digressions allow students, as a community of learners, to take ownership of their learning process.".

According to Glasersfeld (1981), the concept of "truth" in constructivist discussions has been replaced by "viability". Terms, theories, and cognitive structures are regarded as "viable" as long as they - more or less reliably - serve a purpose. Constructed knowledge must withstand a viability test: it does not make sense, if it is not viable. Patry (2001) believes that in an educational setting, this "check for viability" should be carried out by students themselves, true to constructivist spirit.

Patry's undergraduate course "Theories and meta-theories of learning" at the department of education of the university of Salzburg, Austria, is delivered in the form of e-learning, with optional face-to-face lectures. The discussion fora of the course are the places where students are expected to check their acquired knowledge for viability. The checks are initially prompted by the moderators, with the hope that students gradually take over in prompting each other.

The e-learning platform used by the department of education at the university of Salzburg is Blackboard, which is also the university's main learning platform. Students of the department of education are required to become familiar with it as many courses make use of it. The discussion fora of Patry's course typically counts thousands of discussion threads per term. Quantity and quality of students' contributions are evaluated and have an impact on the students' scores.

The challenge of determining whether the moderators manage to reduce their roles in the discussions, and how this is achieved, is the main topic of this paper.

\section{Educational aspects}

Students are not equally comfortable with discussions taking place in the form of asynchronous communication, as is the case in online discussion fora. Common complaints include lack of personal contact, anonymity and - sometimes - too many contributions to a given topic. The underlying reasons are not necessarily because of the communication being asynchronous, but because of the means being impersonal. Herring (1999) in her discussion of asynchronous computer communication, lists two properties that are often cited as obstacles: "(1) lack of simultaneous feedback, caused by reduced audio-visual cues 
and the fact that messages cannot overlap; (2) disrupted turn adjacency, caused by the system, without regard for what they are responding to".

On the positive side, asynchronous communication can involve more participants than face-to-face discussion groups. Partial or full anonymity regarded as disadvantage by some participants can also be of advantage to those who, due to minority membership, gender, religion, or otherwise may hesitate to participate in active discussion. Here, partia anonymity is referred to when students know each other by face but not necessarily by name. Learners who may not be as articulate as others have a better chance of making contributions to the discussion. Another advantage, often overlooked, is the fact that discussion fora result in a record that can be reflected on again at any time later.

At this point, a brief excursion regarding terminology may prove useful. When describing Internet discussion fora, the term computer-mediated communication is often used in literature. Is the use of the term -mediated indeed justified when referring to Internet discussions? As a wide range of related terms, such as -based, -aided, -supported, etc, are often used interchangeably, it may be well worth to follow the definitions suggested by Anohina, who regards the term -mediated as the broadest of connectives, defining it as "some technology [that] is used as a learning resource or a tool, as a tutor and as a subject to be taught." (Anohina, 2005). A connective in this context is part of the following construction scheme: a technology describing word + connective + an educational concept, as in the term computer-mediated communication.

When a technology "is used as a means of learning, that provides presentation of the learning materials, checks the learner's knowledge, guides questioning-and-answering sessions, as well as develops recommendations for further learning direction", Anohina suggests the connectives -aided and -assisted. It is this author's contention that, following Anohina's definitions, one of the latter two terms should be used when employing discussion fora within constructivist teaching; -assisted will be the one used in this text. According to the same definitions, Patry's educational concept in this course can be regarded as resource-based, as "it is learners, not the teacher, who have a central role in the learning process".

Several cases have been written in literature so that computerassisted communication is considered as representing social networks, where social network rules apply. One such case is found in Garton, Haythornthwaite, and Wellman (1999), quoted by Knuppel (2000): "When a computer network connects people or organizations, it is a social network. .. a social network is a set of people (or organizations or other social entities) connected by a set of social relations, such as friendship, co-working, or information exchange". Viewing online-discussion contributions as social interactions, and as a result, the discussion participants as social network, may be of interest not only to the constructivist teacher. Teachers and/or mentors may wish to know how successful they are in gradually moving away from the center of discussions (threads) to assume a less prominent role. For a few dozen threads this can be easily done by simple observation; however, a full-term course may easily generate hundreds of threads containing thousands of contributions. When considering online discussions as social networks, it would make sense to use social network methods for their analysis. The graphic presentation of threads can be particularly useful, as it will be shown. 


\section{Operational aspects}

One of Blackboard's strengths lies in the administration of large amount of students and courses in tertiary educational institutes. Less functional emphasis is given to matters of content management and testing. TeachNOW, a relatively new e-learning platform, has recently added functions that allow integration with Blackboard through an XML-interface, and indeed with all e-learning platforms that allow XMLcompatible content sharing. In its present implementation (version 2.15), TeachNOW is capable of scanning Blackboard archives for discussion fora and exporting suitably formatted data to be used as input files for the social network software UCINET. Optionally, contributors' names can be edited in the process, and various other properties can be assigned, such as gender of the contributor, weight of the contribution (e.g., considering quantity, quality, or whether made by teacher or student). A quantitative analysis of the threads containing number of contributions and words used by student can also be extracted.
The interoperability of UCINET, TeachNOW and Blackboard (and all other XML-compatible platforms for that matter) allows for several possible scenarios. One such scenario is shown in Figure 1, which depicts a practical example of how a particular discussion thread, taken from an actual course, has been analyzed using social network methods to produce graphical presentations of the discussion threads. The aim is to look at the lecturer (in this context referred to as moderator) and determine how central his or her role is in a particular discussion. This is especially useful when online discussions are a key learning means, as can be the case in constructivist teaching. Trends, otherwise not easily visible, can become apparent when comparing a sufficient number of threads over a period of time.

The following scenario, depicted in Figure 1, shows only two types of actors: moderator and students. In the practice, the extraction of the thread contents using TeachNOW (which can also be done manually) and the analyses using UCINET can be carried out by teaching staff other than a moderator.

Figure 1. From discussion thread to graphical representation

\begin{tabular}{|c|c|c|c|}
\hline Software & Blackboard & TeachNOW & UCINET \\
\hline Actor(es) & moderator, students & moderator & \\
\hline $\begin{array}{c}\text { Identify } \\
\text { threads }\end{array}$ & $\begin{array}{c}\text { Archived discussion } \\
\text { threads (XML format) }\end{array}$ & & \\
\hline $\begin{array}{c}\text { Convert to UNICET } \\
\text { format }\end{array}$ & & $\begin{array}{c}\text { Conversion functions } \\
\text { (or manually) }\end{array}$ & \\
\hline Output graphics & & & Netdraw function \\
\hline
\end{tabular}

Source. Prepared by the author 


\section{Study case: from students"} discussion contributions to graphic thread presentations

In the preceding chapters, the structure of an e-learning course at the university of Salzburg, Austria, has been outlined. Some salient facts of an actual course that took place during the winter semester 2013/14 are now presented. The graphical thread analyses were carried out using the social network software UCINET. Some functions from the learning platform TeachNOW were used to convert the Blackboard discussion forum format (XML) suitable for its input into UCINET. In practice this can also be done manually.

Students were given a 92-page reader to refer to, and were able to take advantage of optional face-to-face lessons throughout the course. A total of nine assignment topics were consecutively placed on the Blackboard discussion board. Students generated a total of close to 500 discussion threads, containing approximately 4000 contributions. Patry and a teaching assistant - both forthwith referred to as moderators - contributed to the discussions with guidance and suitable prompts to encourage students to check acquired knowledge for viability.

The quality and quantity of the contributions were taken into consideration when calculating students' scores at the end of the course. To collect the necessary data, the moderators were initially required to go through the discussion contributions manually to extract the necessary values, which proved to be a rather time-consuming task. Practically impossible to ascertain without automated means was the degree to which moderators were able to ease themselves out of the center of discussions. A solution employing social network methods was adopted, allowing the graphic representation of social networks. UCINET, from Borgatti, Everett, and Freeman (1999), is an example of social network software that supports such graphic presentations. Another social network software that was considered for this purpose was StOCNET, which is described as "an open and user-friendly software system for the advanced statistical analysis of social networks, focusing on probabilistic (stochastic) models" by their authors Boer, Huisman, Snijders, Steglich, Wichers, and Zeggelink (2003). StOCNET scores very high on usability and its capability of implementing a range of theoretical models that are well documented, but has no network visualization methods. As such it is better suited in the hands of statisticians who wish to carry out advanced analyses.

For this particular environment, where several software systems are expected to interoperate seamlessly and transparently, UCINET seemed to be the best choice. A thorough and up-to-date discussion of available software for social network analysis can be found at Huisman and Van Duijn (2004). Another very useful text on social network analysis, with many references to UCINET, is Scott (2013).

The task at hand right now is to produce the required UCINET-compatible data input files, unfortunately, a quite daunting one when done manually; indeed it would not be realistic to assume that teaching staff would have sufficient resources available to do so. 
The e-learning platform TeachNOW on the other hand, in addition to providing an XML-interface to Blackboard's discussion fora, makes social network methods accessible through the generation of data files that are suitable for input into UCINET. The moderators of the course are required to go through the following steps to produce graphical output, allowing them to take a "social network" view of the discussion threads:

- At any time during or after teaching, use standard Blackboard features to archive the discussion forum in question. This makes forum discussion details available in XML-format. Figure 2 below shows an extract of one particular thread, stripped off XML-tags that are irrelevant for this discussion.

The actual entries by the moderator and students are shown in bold, the remaining text is XML-tags that are relevant for the discussion. The moderator named this particular forum "Assignment 2: educational situations", followed by the instructions "Post your comment ...". The moderator also started the first thread and called it "active and passive situations".

In this particular thread, the first entry was made by AngelikaF: "... my question: ... " (not shown completely). The first entry, which is also called seed entry, is not directed to anyone in particular. SonjaB followed with the response "I think ..." (not shown completely). This response is directed to AngelikaF.
Figure 2. Sample from an archived discussion thread (XML format)

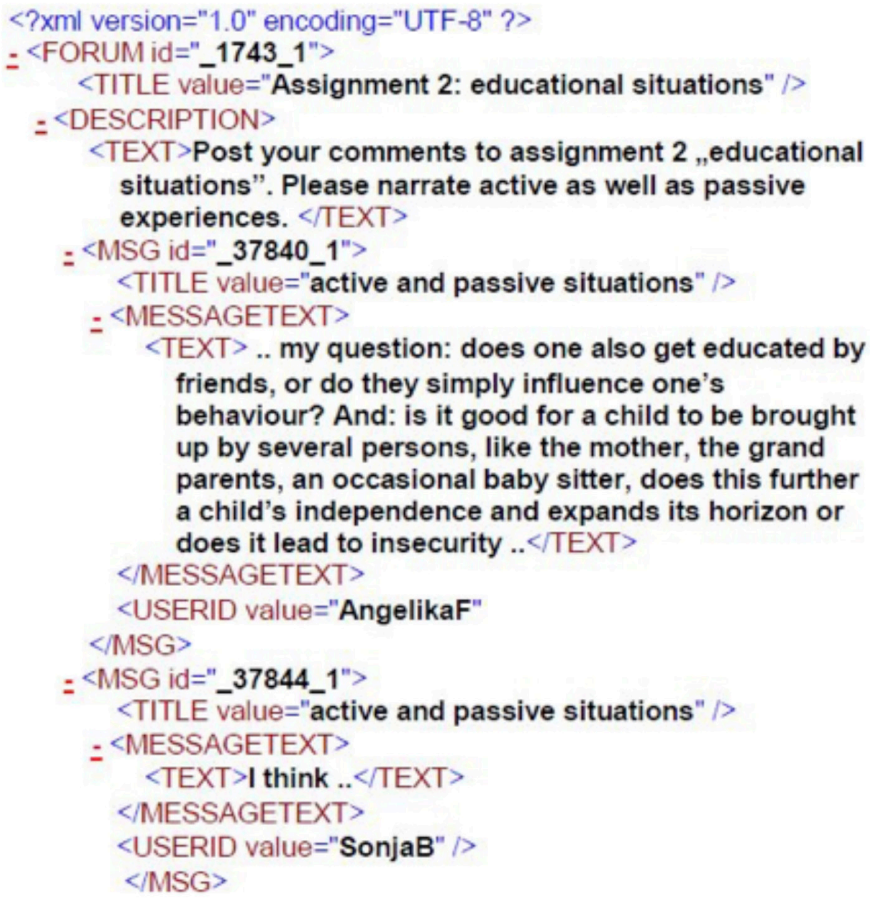

Source. Prepared by the author

- From TeachNOW (or manually), import the XML-files, optionally modify contributor names and add properties, and produce a TeachNOW-compatible forum. Produce a UCINET- input data file, as shown in Figure 3.

While it is not important to understand the file's header information in detail, some aspects of the data part require explanation. Firstly, each entry depicts a directed communication (i.e., the first line indicates that SonjaB had something to say to AngelikaF), as can also be 
seen from the Blackboard archive above. AngelikaF's seed entry was not directed to anyone in particular and is therefore simply ignored for this analysis. This also follows Herring (1999), who does not perceive the first thread contribution in a discussion as interaction.

References made to " $\mathrm{M}$ " denote communication with the moderators.

Figure 3. Import file for UCINET

$\mathrm{dl} n \mathrm{nr}=5, \mathrm{nc}=5$, format $=$ edgelist1

Labels:

AngelikaF, AngelikaS, BettinaM, SonjaB, M

row labels embedded

data:

SonjaB AngelikaF

$M$ SonjaB

BettinaM M

AngelikaS BettinaM

M BettinaM

AngelikaF M

SonjaB BettinaM

Source. Prepared by the author

- Produce a graphical presentation of the thread with the NetDraw - module of UCINET, using standard settings. The input file shown in Figure 3 produces the output shown in Figure 4.

This thread was the first one that was established in the course, and the second of a total of nine assignments throughout the course. It was a rather short one during which BettinaM's comment to the moderators elicited three comments to her made by other students. The moderator, along with SonjaB, also had a reasonable share in the communication.

There were only few contributions, and about half of them were made directly to the moderator or came from him (the point marked " $\mathrm{M}$ " at the bottom of the graph). Remember that one of the tasks of the moderator is to gradually withdraw himself from the discussions.

Figure 4. Graphical representation of a Blackboard thread

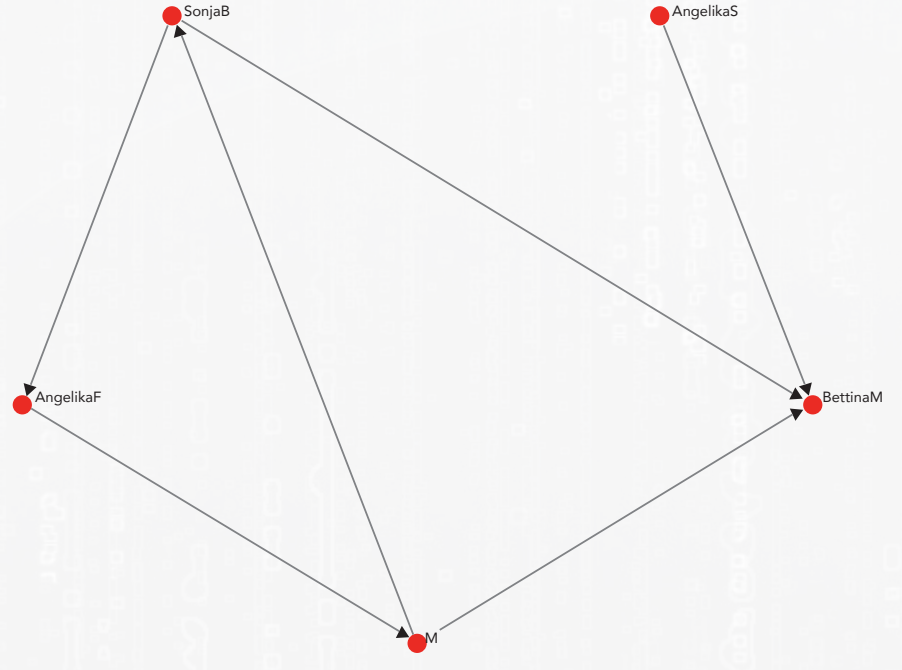

Source. Prepared by the author 
In practice, single threads would rarely be analyzed by themselves, unless they contain a large number of contributions. Typically, a number of threads that were established over the time of the course would be selected for analysis.

To give an impression of how moderators could use such graphical thread representations to better understand the dynamics of their group of students, three more threads of a total of 59 threads - of the same assignment are briefly discussed.

Figure 5. Graphical representation of thread 27, assignment 2

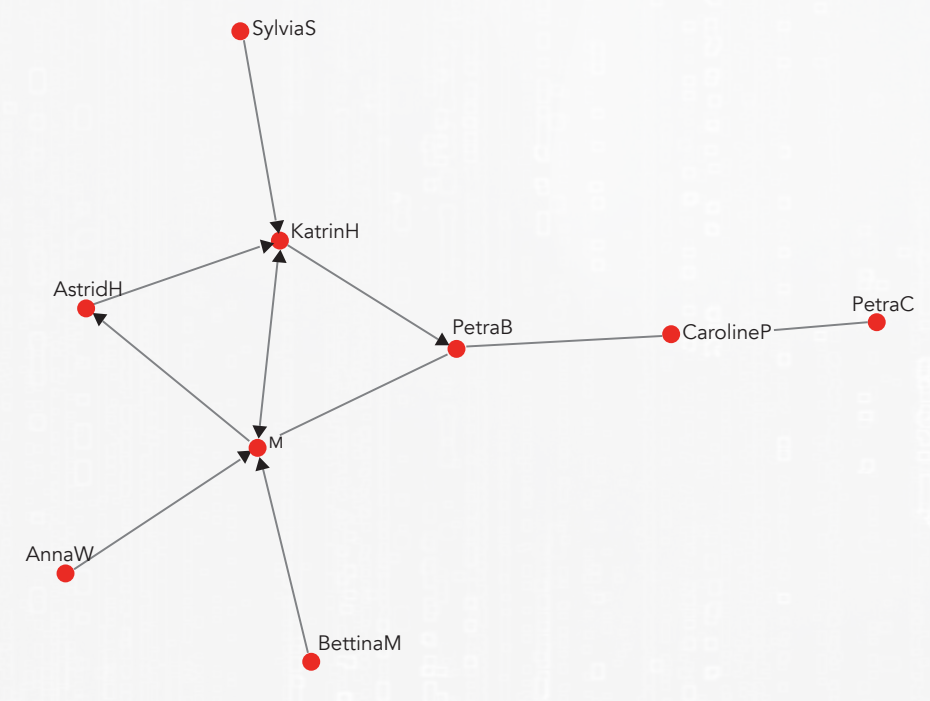

Source. Prepared by the author
Figure 6. Graphical representation of thread 41, assignment 2

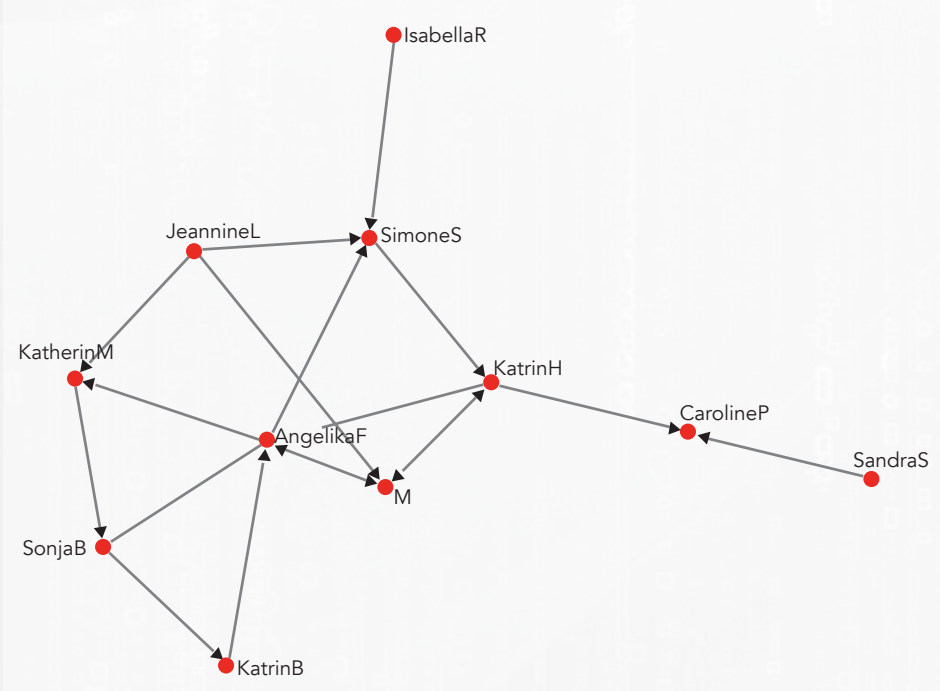

Source. Prepared by the author

The presence of the moderators in threads 27 (as shown in Figure 5) and 41 (as shown in Figure 6) are about the same; the latter thread, however, clearly shows a much higher student participation. Again, and as it can also be seen from other threads that are not presented here, show some students appeared to be quite willing to assume the moderators' role.

As a last example, thread 50 is shown in Figure 7. It is one of the threads in which the moderator did not participate at all. 
Figure 7. Graphical representation of thread 50, assignment 2

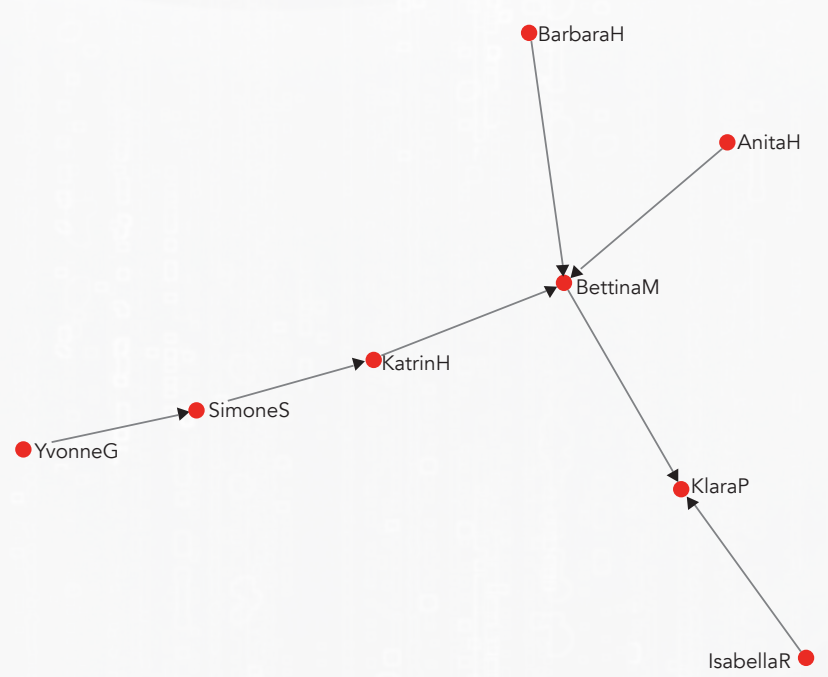

Source. Prepared by the author

\section{Discussion}

The use case that was presented in this document showed one of several possible scenarios of the educational interoperating systems Blackboard, TeachNOW and UCINET. Blackboard, the platform with which both moderators and students were comfortable using; it was the single vehicle used for the learning processes. The social network software UCINET was used to present social aspects of the thread that would have likely gone unnoticed otherwise. The preparation of UCINET compatible data files - possibly done manually albeit very time- consuming - was handled by TeachNOW; its capability to read Blackboard archives was an additional advantage.

It should be pointed out that teaching staff were clear from the outset of what they wanted to achieve for themselves. Apart from students' learning success, teachers aimed for their own gradual removal from the center of discussions towards a less prominent role, in the spirit of constructivist teaching. To measure that change of role, discussion threads were presented graphically.

While it is true that the three educational systems that were used in the task are interoperable, in the sense that the individual task steps are carried out semi-automatically, it is also apparent that there is room for improvement to further automate the process. In the present scenario, there were two simplifications in the way this process was carried out.

First, there is an educational aspect. Each contribution to the discussions was treated with the same level of importance. This, of course, is acceptable when viewing discussions strictly as "social network" and is also in line with the argument of Ugoretz - who had been quoted earlier in the defense of digressing discussions by students - that "instructors should give equal weight to all acceptable types of response" (Ugoretz, 2005). However, AngelikaF's question in the first thread whether "it is good for a child to be brought up by several persons" has a rather different level of quality compared to a contribution that may consist of a simple "well, I don't really know" and obviously, it also has a different impact on the further development of the thread. 
This question posed by AngelikaF is a classic example of what Patry was trying to achieve his students to do: taking the initiative for prompting fellow learners to find a solution to a problem. The next stage would be to test forthcoming solutions constructed knowledge in constructivist language) for viability, and, of course, finding criteria for such tests. The aforementioned demonstrates that it would be required to attach properties to each communication in certain situations, which could be done by appending values, such as 1-for prompting for a viability check, 2- for carrying out a viability check, 3- for a general comment, and so forth. UCINET input data would then look something like:

\section{SonjaB AngelikaF 1}

M SonjaB 2.

Therein lies the second aspect of the above-mentioned simplification, namely, no such properties were attached. There is no problem in handling several such properties on the part of UCINET. However, during the process of TeachNOW generating UCINET-compatible data files some editing would need to take place. At present, this would be done by manually adding the values in the generated files, using a simple text processor or the UCINET spreadsheet editor, for example. Although technically straight-forward, it requires intermediate steps by the teacher who would probably first put down these values with paper and pen during the qualitative analysis of the discussion threads. A much more comfortable way would be some sort of "in-line editing" of the thread contributions, while reading through them. There is ongoing further development by the TeachNOW team to add new functionality to this effect. However, the mere appending of values to discussion contributions is only half the work. Attributes need to be made separately known to NetDraw, the UCINET module that is responsible for graphical output. To further automate the whole process, the NetDraw module should no longer be executed interactively but run in a parameter-driven batch mode.

\section{Some possible improvements}

Often, novel ideas get buried under the mass of discussion contributions as the course proceeds. One would wish for some kind of extraction method to separately save specific parts of the discussions. A suitably extracted text could then be used by moderators as additional teaching resource, and by learners as testimony and proof of progress, which they may wish to include in their portfolio. TeachNOW supports ePortfolios for students as a teaching and learning tool in its own right, and to acknowledge the fact that "the use of ePortfolios in distributed learning in compulsory and higher education worldwide has increased dramatically over the last five years", as stated by IMS (2004), who define ePortfolios as "a collection of authentic and diverse evidence, drawn from a larger archive, that represents what a person .. has learned over time ..".

High up on the wish list for improvements is therefore a set of features that allow users to easily manipulate discussions by:

- appending properties to discussion contributions (e.g., values), discussion threads (e.g., date / time), and participants (e.g., role, gender) 
- highlighting parts of contributions for the purpose of extracting/summarizing and word count; it should also be possible to attach properties to such highlighted parts.

At present, the integration of the Blackboard and TeachNOW learning platforms requires Blackboard archiving as an intermediate step. For the described scenario this poses no problem as archiving is done with a few mouse clicks. However, it would not be possible for moderators and students to use the discussion boards of both learning platforms according to their preference, and to have instant access to updated contents. To achieve this, Blackboard Building Blocks would have to develop that "hook" directly into Blackboard through an application programming interface. As this requires considerable effort, such development is not expected to be available in the near future; while this happens, a more economical strategy could be to work on additional flexibility of the TeachNOW end of the interface. Making formative evaluations of their course as the course progresses in addition to a summative evaluation at the end of the course would make it more conducive for teaching staff.

\section{URL's of educational systems employed}

\section{E-learning platforms:}

Blackboard: http://www.blackboard.com

TeachNOW: http://www.irmler.at

\section{Social network software:}

UCINET: http://www.analytictech.com

\section{Free download at:}

https://sites.google.com/site/ucinetsoftware/downloads

\section{Youtube introduction to UCINET in Spanish:}

https://www.youtube.com/watch?v=JqQFnCOHVx4 


\section{References}

Anohina, A. (2005). Analysis of the terminology used in the filed of virtual learning. Educational Technology \& Society, 8 (3), 91102.

Boer, P., Huisman, M., Snijders, T.A.B., Steglich, C.E.G., Wichers, L.H.Y., \& Zeggelink, E.P.H. (2003). StOCNET: An open software system for the advanced statistical analysis of social networks. Version 1.4. Groningen: ProGAMMA/ICS. Retrieved from http://stat/gamma.rug.nl/stocnet/

Borgatti, S.P., Everett, M.G., \& Freeman, L.C. (1999). UCINET 6.0 Version 1.00. Natick: Analytic Technologies.

Brown, J. S., Collins, A., \& Duguid, P. (1989). Situated cognition and the culture of learning. Educational Researcher, 18 (1), 32-42.

Garton, L., Haythornthwaite, C., \& Wellman, B. (1999). Studying On-Line Social Networks. In S. Jones (Ed.), Doing Internet Research: Critical Issues and Methods for Examining the Net (75-105). Thousand Oaks, CA: SAGE Publications,.

Glasersfeld, E.V. (1981). The concepts of adaptation and viability in a radical constructivist theory of knowledge. In: Sigel, I., Glinkoff, R., \& Brodzinsky, D. (eds.). New directions in Piagetian theory and their application to education. Hillsdale, NJ

Herring, S. (1999). Interactional Coherence in CMC. Journal of Computer Mediated Communication, 4(4). Retrieved from http://www. ascusc.org/jcmc/vol4/issue4/herring.html\#ADVANTAGES
Huisman, M., \& Van Duijn, M.A. (2004). Software for social network analysis. In: P.J. Carrington, J. Scott, \& S. Wasserman (eds.), Models and methods in social network analysis. Cambridge: Cambridge University Press.

IMS (2004). ePortfolio Best Practice and Implementation Guide, revision: 20 September 2004. Retrieved from http://www. imsglobal.org/ep/epv1p0pd/imsep_bestv1p0pd.html

Knuppel, M. (2000). A characterization of the Linux community of practice using Linux newsgroups and Bales' Interaction Process Analysis. Retrieved from http://www.scholar.google.com/ scholar?hl=en\&lr=\&q=cache:RLZoi29CzlkJ:neoref.ils.unc. edu/2622.pdf+bales+ipa

Patry, J.L. (2001). Die Qualitätsdiskussion im konstruktivistischen Unterricht. In: Schwetz, H., Zeyringer, M., \& Reiter, A. (Hrsg.), Konstruktives Lernen mit neuen Medien. Beiträge zu einer konstruktivistischen Mediendidaktik (73-94). Innsbruck: StudienVerlag.

Scott, J. (2013). Social Network Analysis, (3rd ed.). London: Sage.

Ugoretz, J. (2005). "Two roads diverged in a wood": Productive digression in asynchronous discussion. Innovate: Journal of Online Education, 1(3), 7. Retrieved from http://www. innovateonline.info/index.php?view=article \&id=30

Wideman, H.H. (n.d.). Creating a Learning Community: Using ICT to Enhance Constructivist Teaching Practice at Mountview School. Retrieved from http://sitesm2.org/sitesm2_search/ docs/CA002_narrative.pdf 